\title{
One-stage bone strip reconstruction technique with balloon sinus dilatation surgery for chronic maxillary atelectasis
}

This article was published in the following Dove Press journal:

Clinical Ophthalmology

25 November 2016

Number of times this article has been viewed

\author{
Tomoyuki Kashima' \\ Robert A Goldberg' \\ Jocelyne C Kohn² \\ Daniel B Rootman' \\ 'Division of Orbital and Oculoplastic \\ Surgery, Stein Eye Institute, University \\ of California, Los Angeles, CA, USA; \\ ${ }^{2}$ Pasteur Ophthalmology Clinic, \\ Oculoplastic, Orbit and Lacrimal \\ Service, Santiago, Vitacura, Santiago \\ Metropolitan Region, Chile
}

Purpose: Chronic maxillary atelectasis is characterized by unilateral spontaneous enophthalmos and hypoglobus due to increased orbital volume secondary to maxillary sinus inward deformation. Reformation of the sinus architecture and reconstruction of the orbit are key to a successful outcome. Here, we introduce a one-staged surgery that addresses both these goals.

Patients and methods: We retrospectively reviewed 11 patients treated with one-stage orbital and sinus surgery. A transconjunctival subperiosteal approach was used to create slats in the thinned orbital floor. A nasal endoscopic approach was utilized to access the maxillary sinus and place a modified Foley catheter balloon through the enlarged maxillary ostium. A bridge graft of nasal septal, ear cartilage, or LactSorb was placed on the reconstructed and balloonsupported orbital floor. The balloon was deflated and removed at 10-14 days. All patients underwent complete ophthalmic and orbital evaluation, including standardized photography and radiologic imaging.

Results: Eleven patients, mean age 39.5 years, presented with diplopia in upgaze, superior sulcus deformity, and at least $2 \mathrm{~mm}$ of relative enophthalmos. After initial overcorrection, enophthalmos improved in all cases. Symmetry within $1 \mathrm{~mm}$ was accomplished in 10 of 11 cases. Follow-up time was $259 \pm 320$ days. Full motility was recovered in all patients.

Conclusion: We describe a one-staged surgery consisting of cutting slats in the orbital floor, dilating the maxillary sinus with a balloon, and stabilizing the orbital floor with a cartilage graft placement. Our anecdotal experience suggests that this surgical approach can safely achieve normalization of the pathologic sinus outflow and restoration of the orbit anatomy. The balloon ensures orbital floor stability during the healing process, and it may act to stent open the sinus ostium during early mucosal healing.

Keywords: silent sinus syndrome cartilage graft, orbital floor, remodeling

\section{Introduction}

Chronic maxillary atelectasis (CMA) or silent sinus syndrome is a rare disorder characterized by inward deformation of the maxillary sinus walls producing spontaneous enophthalmos and hypoglobus., ${ }^{1,2}$ Various hypotheses of the underlying mechanisms have been proposed, the most commonly accepted being that the occlusion of the maxillary sinus generates negative pressure and that this triggers the thinning and deformation of the bony walls. ${ }^{3}$ Endoscopic antrostomy is commonly used to reaerate the sinus. ${ }^{4-8}$ There is no consensus regarding the need for orbital reconstruction, the timing, and the ideal technique. ${ }^{9}$ In CMA, the radiographic appearance of the orbital floor is reported to present patchy demineralization, decreased bone density, and dramatic thinning. $1,9,10$
Correspondence: Robert A Goldberg Division of Orbital and Oculoplastic Surgery, Stein Eye Institute, University of California, 300 Stein Plaza, Los Angeles, CA 90095 , USA

Tel + I 3102068250

$\mathrm{Fax}+\mathrm{I} 3108259263$

Email goldberg@jsei.ucla.edu (c) (1) (-) 2016 kashima et al. This work is published and licensed by Dove Medical Press Limited. The full terms of this license are available at https://www.dovepress.com/terms.php cc) ${ }_{\mathrm{BY}} \mathrm{NC}$ and incorporate the Creative Commons Atribution - Non Commercial (unported, v3.0) License (http:///creativecommons.org/licenses/by-nc/3.0/). By accessing the work you hereby accept the Terms. Non-commercial uses of the work are permitted without any further permission from Dove Medical Press Limited, provided the work is properly attributed. For permission for commercial use of this work, please see paragraphs 4.2 and 5 of our Terms (https://www.dovepress.com/terms.php). 
Here, we introduce a one-staged surgery that addresses remodeling orbital floor using bone strip technique with maxillary reconstruction.

\section{Patients and methods}

\section{Patients}

The charts of all patients undergoing surgery for CMA with orbital cartilage graft and balloon sinus dilatation at the Division of Orbital \& Ophthalmic Plastic Surgery at the Jules Stein Eye Institute between July 2009 and July 2015 were reviewed. All patients underwent complete ophthalmic and orbital evaluation, including visual acuity, assessment of extraocular motility, Hertel ophthalmometry, photography, and radiologic imaging.

\section{Surgical technique}

All operations were performed under general anesthesia along with local injection of lidocaine $1 \%$ with epinephrine and nasal packing soaked in oxymetazoline $0.05 \%$. A transconjunctival approach was used to access the orbital floor in the subperiosteal plane. Using a \#15 Bard Parker blade, 4-5 anterior-to-posterior slats, $4 \mathrm{~mm}$ wide, were created in the thinned orbital floor bone (Figure 1A). The slats were parallel to the infraorbital canal, sparing the infraorbital nerve (which was easily visualized in the thinned bone) and sparing the sinus mucus membrane. A graft was harvested from the ear cartilage from the scaphoid fossa and antihelix $(n=3)$ as wide as $\sim 7 \times 35 \mathrm{~mm}^{2}$ or quadrangular cartilage from the septum $(\mathrm{n}=7)$ in the septoplasty manner as wide as $20 \times 40 \mathrm{~mm}^{2}$ plane, trimmed, and placed as a bridge over the orbital floor to attach all bone strips as a beam (Figure 1B). In one patient, a resorbable poly-L-lactic acid/polyglycolic acid (PLLA-PGA) copolymer (LactoSorb) was used instead of a cartilage graft. An endoscope was then utilized to access the middle meatus.
A right-angled hemostat was placed into the meatus, and the ostium was enlarged as required using a rongeur. The bone strips of the orbital floor were positioned to override each other in the manner of a Chinese fan. A Foley balloon catheter, modified by cutting the tip beyond the balloon, was inserted into the maxillary sinus (Figure $1 \mathrm{C}$ ) and filled with $5-7 \mathrm{~cm}^{3}$ of saline. The globe position at the end of the procedure was titrated to overcorrect the enophthalmos by $1 \mathrm{~mm}$, anticipating shrinkage during remodeling of orbital bones. After placement of graft or implant, the periosteum and palpebral conjunctiva were left without suturing. The distal end of the Foley was then tied firmly with a 2-0 silk tie, to maintain fluid in the balloon, and cut at the nostril. The balloon was removed in 10-14 days, by cutting above the silk suture to allow the water to drain out of the balloon (Figure 2A-C). Statistical significance was calculated using a Student's $t$-test (Excel 2013; Microsoft, Redmond, WA, USA). Written informed consent was obtained from all patients. Ethics approval was obtained from UCLA (University of California, Los Angeles) Institutional Review Board for the study. The research was conducted in adherence to the tenets of the Declaration of Helsinki, and all patients gave informed consent to have their photographs published.

\section{Results}

Eleven patients (10 male), mean age 39.5 years (range 23-62 years), had a diagnosis of maxillary atelectasis and underwent the described surgery. It affected the right eye in 6 cases and the left eye in 5 cases. All 11 patients noticed periorbital asymmetry (100\%). Eight of 11 patients presented $<1$ year after the beginning of the symptoms, and 4 recalled past history of minor orbital trauma $(>1$ year prior with no history of orbital fracture) and 4 of chronic sinusitis. Two patients had undergone prior sinus surgery for recurrent sinusitis. Five presented with diplopia in

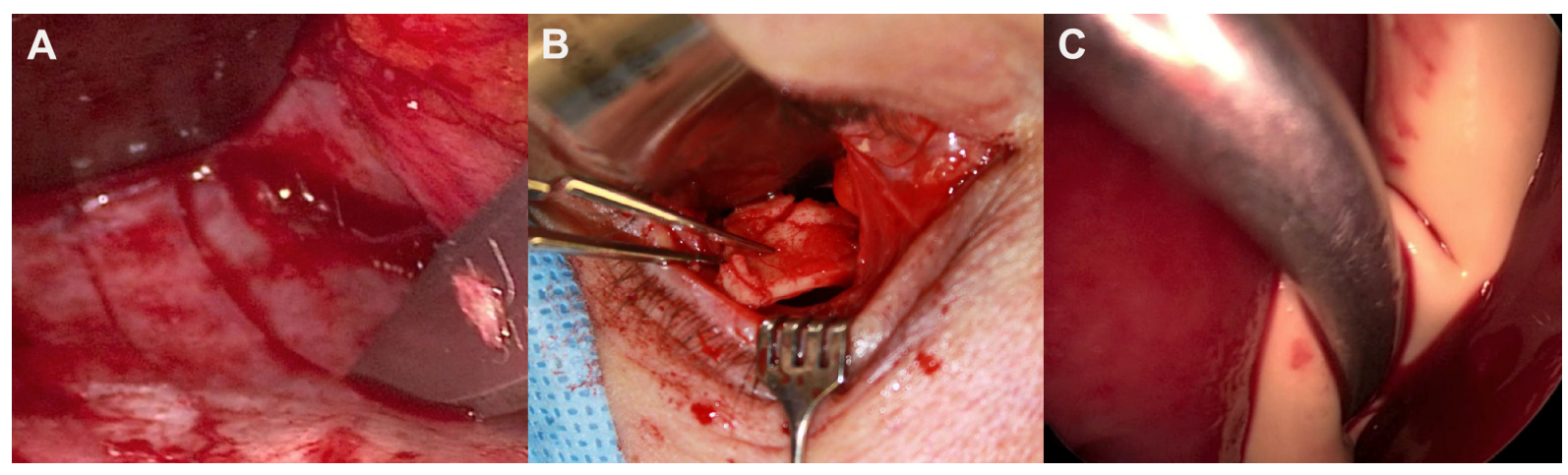

Figure I The manner of bone strip surgery.

Notes: (A) The orbital floor is accessed through a transconjunctival approach; slats are cut using a \#I5 Bard Parker blade. (B) Ear cartilage positioning over the orbital floor slats. (C) Insertion of the balloon to the maxillary sinus after enlargement of the osteomeatal ostium. 


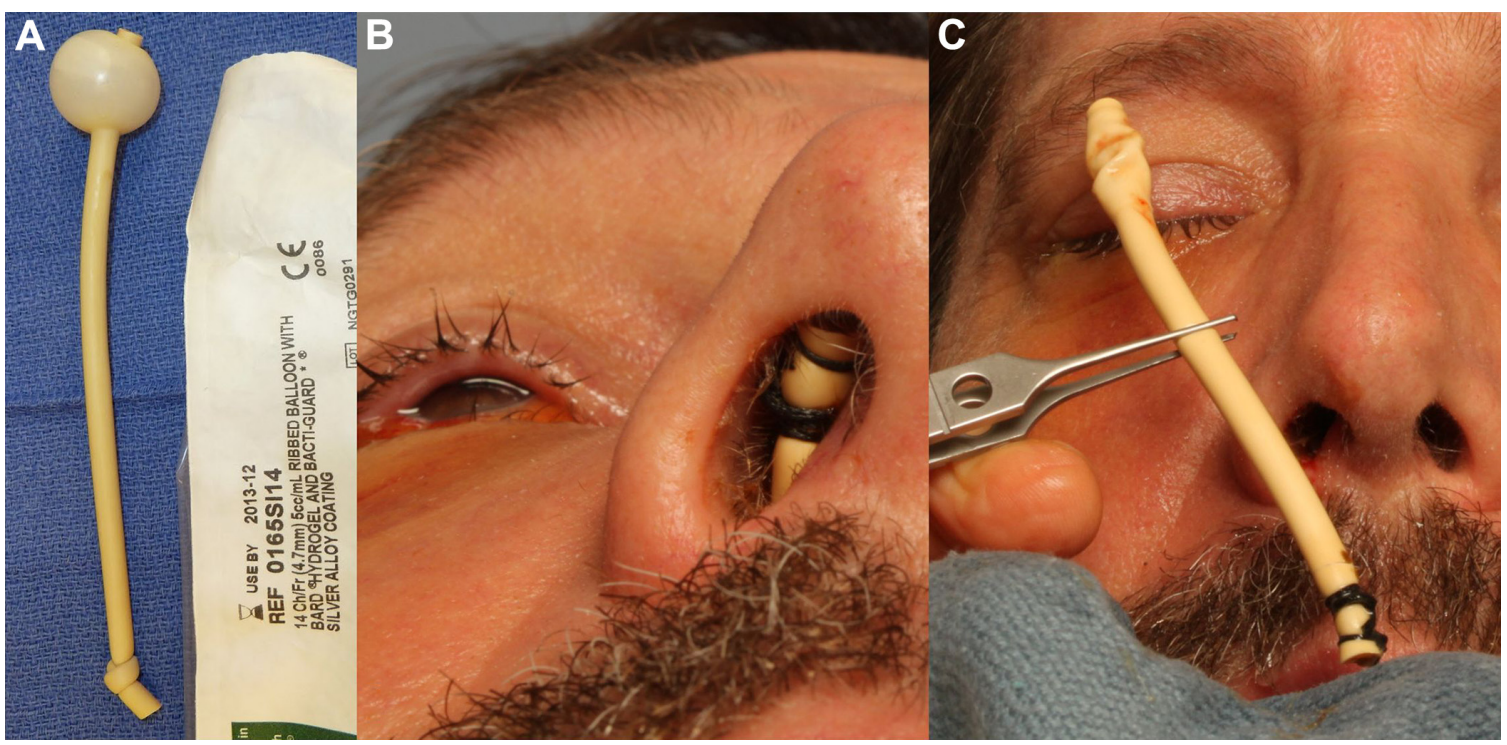

Figure 2 Balloon insertion and extraction.

Notes: (A) Modified Foley catheter, the tip is cut beyond the balloon. (B) Balloon in position in the maxillary sinus, distal end in the nostril. (C) Balloon is easily removed by letting the saline out.

upgaze and 2 with orbital pressure and pain. Preoperative examination revealed superior sulcus deformity and at least $2 \mathrm{~mm}$ of relative enophthalmos (average: $2.5 \mathrm{~mm}$ and range: 2-3 mm) in all patients.

Median and average follow-up periods following surgery were 15.4 weeks and $37 \pm 45.7$ weeks, respectively (range 2-155 weeks). Postoperative relative enophthalmos was significantly improved in all cases (mean $2.0 \mathrm{~mm}$ and range: $1.0-4.0 \mathrm{~mm} ; P<0.0001$; Figures 3 and 4). Ten patients (91\%) achieved symmetry within $1 \mathrm{~mm}$, except for 1 patient who was settled as $-2 \mathrm{~mm}$. All five cases with diplopia improved after surgery. The postoperative self-limited complications observed immediately after surgery were chemosis $(n=1 ; 9 \%)$, tooth pain $(n=1 ; 9 \%)$, and infraorbital

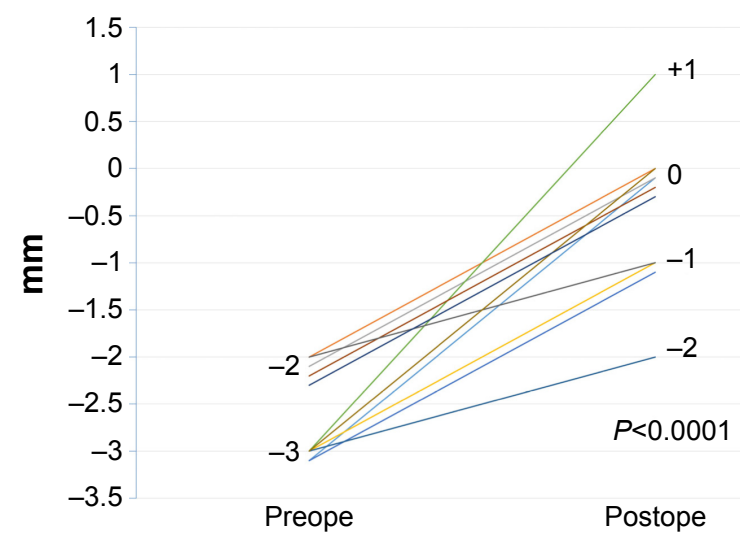

Figure 3 Data of relative enophthalmos pre- and postsurgery.

Notes: All patients improved asymmetry postoperatively $(\mathrm{N}=\mathrm{II})$. Mean improvement of ophthalmometry is $2.5 \mathrm{~mm}$.

Abbreviations: preope, preoperative; postope, postoperative. hypoesthesia $(\mathrm{n}=3 ; 27 \%)$. Complications that required surgical management were infectious sinusitis $(n=1 ; 9 \%)$, $1 \mathrm{~mm}$ over correction $(\mathrm{n}=1 ; 9 \%)$, lower eyelid retraction $(\mathrm{n}=1 ; 9 \%)$, and nasolacrimal duct obstruction $(\mathrm{n}=1 ; 9 \%)$. There was no relationship between the surgical result and the materials used in orbital floor reconstruction.

\section{Discussion}

We propose a one-staged surgery based on unpredictable improvement reported with sinus reaeration surgery alone. Sivasubramaniam et $\mathrm{al}^{11}$ reported complete resolution of enophthalmos in $78 \%$ of their patients following endoscopic uncinectomy and maxillary antrostomy. However, the results of this study are difficult to interpret because only 7 patients presented with facial asymmetry and clinical enophthalmos, and there was no objective measurement of exophthalmometry. Two of our cases had successful sinus surgery before presentation but still had residual enophthalmos. Thomas et a ${ }^{12}$ presented a series of 4 cases of isolated sinus aeration and observed a $16 \%$ increase in the sinus volume at postoperative month 9 , but half of the patients required orbital surgery as a second stage. The combined approach is generally preferred at this time, as suggested by Brandt and Wright ${ }^{9}$ when reviewing $31 / 47$ cases treated surgically and Soparkar et $\mathrm{al}^{13}$ who recommended a combined approach after treating 68 cases over the previous 7 years.

The use of a balloon provides early support as a buttress to the reconstituted orbital floor, which may be important during the healing phase. It also allows for intraoperative 


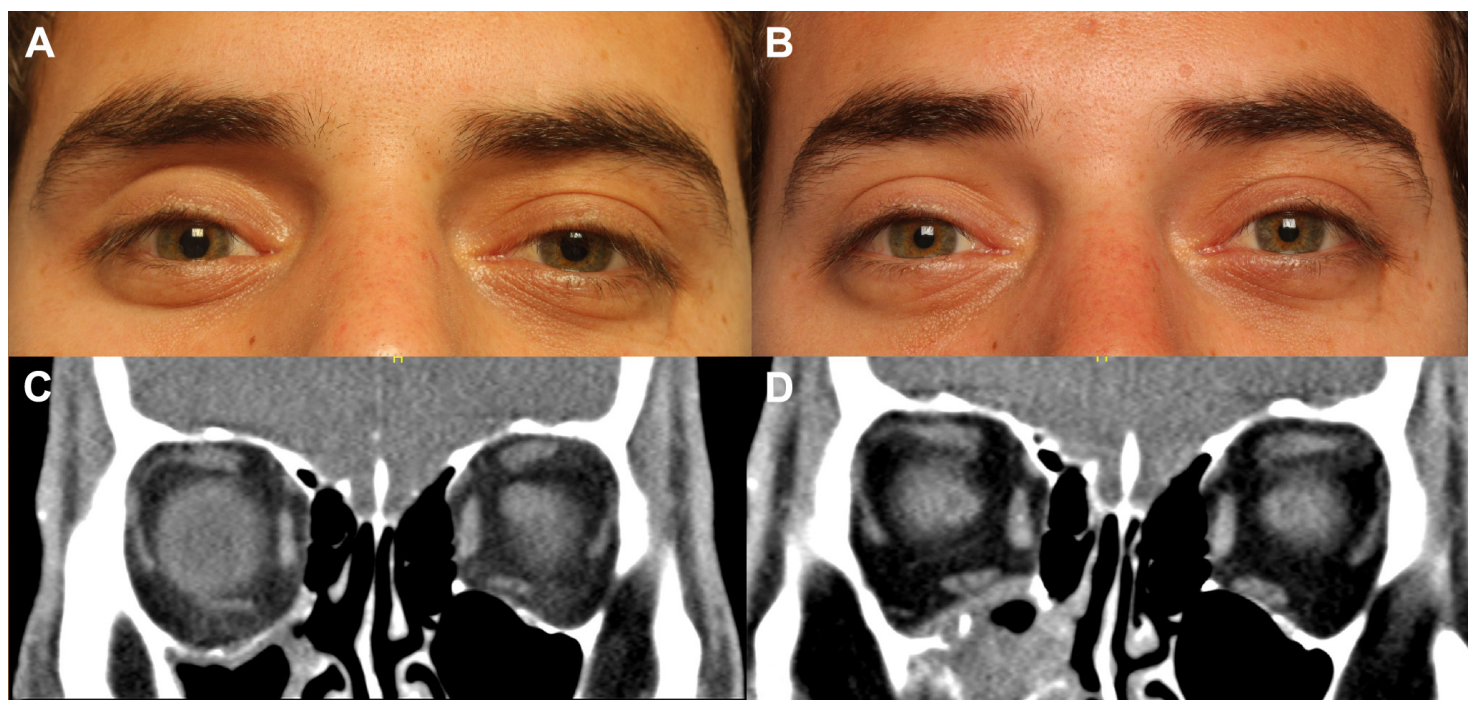

Figure 4 Pre- and postoperative photographs and scans.

Notes: (A and B) Photographs before and 3 months after surgery. (C and D) MRI scans before and 3 months after surgery. (A and B) Right eye shows hypoglobus and superior sulcus deformity. Margin light reflex of right eye looks higher, but the globe is relatively sunken due to hypoglobus. (C) This patient had a history of repetitive maxillary sinusitis before referral. Right orbital floor was rounded and sunken. (D) The orbital floor become thicker and flat due to remodeling surgery. The floor bone was positioned to normal height by the septal cartilage graft.

Abbreviation: MRI, magnetic resonance imaging.

titration, filling the balloon as required in order to correct the enophthalmos. The balloon can also be used as a tool in procedures where the stability of the strut is compromised, for example, in floor and medial wall orbital fracture.

Postoperative relative enophthalmos significantly improved in all cases, although there were some undercorrections. Undercorrection may relate to incomplete orbital reconstruction or to late remodeling of the orbital floor; certainly, the goal at the time of surgery should be to accurately recreate the internal orbital architecture to a normal, or perhaps slightly overcorrected, configuration.

Various implants have been used in CMA to reconstruct the orbit including porous polyethylene, ${ }^{5,14,15}$ silicone block, ${ }^{10}$ Teflon, ${ }^{16}$ bone graft, ${ }^{6,8}$ and even hyaluronic acid gel fillers. ${ }^{17}$ We choose to use cartilage graft because it is an autologous implant and it is easily accessible for surgeons (especially if a septoplasty is also indicated). The graft adds volume, structural support, and forms a scaffold that heals by fibrosis, holding the bony slats in position to reform the orbital floor after the balloon is removed (Figure 5). The graft and implants work as a beam of orbital floor, which means that the graft does not need full width to cover the entire orbital floor. Although it is possible that the periosteum alone would allow the collapsed bone fragments to heal, in our early anecdotal experience before using the additional "beam" graft, undercorrections were more frequent. Absorbable alloplastic implants are another appropriate choice, and we used polydioxanone plate in one case. However, the cartilage graft seems to encourage formation of a stable orbital floor in our anecdotal experience and has the advantage of autogenous material. Thin bone grafts, including perpendicular plate bone, are another choice of material for the beam graft.

Three patients noted pain and numbness in the infraorbital nerve distribution immediately after surgery, presumably related to balloon-induced pressure on the infraorbital nerve, and resolved after the balloon was removed, leaving no permanent damage.

We noted one case of postoperative nasolacrimal duct obstruction, which was successfully treated with endoscopic dacryocystorhinostomy. Chronic atelectasis can distort the sinus anatomy, making it difficult to identify the nasolacrimal duct running on the lateral nasal wall. The anatomy of the nasolacrimal duct should be considered in performing the antrostomy, and in difficult cases, intraoperative nasolacrimal intubation might be appropriately considered.

Postoperative sinusitis was noted only in one patient. Postoperative swelling can obstruct the newly created ostium, and the balloon may serve as a foreign body, exacerbating a postoperative infectious sinusitis. If infection develops, then endoscopic evaluation and mechanical rinsing of the sinus may be indicated, along with antibiotics. However, in our patients, no postoperative antibiotics were prescribed routinely.

Finally, a one-stage "Chinese fan" orbital slat bony floor reduction, orbital beam cartilage graft placement, and balloon sinus dilatation surgery may efficiently achieve reconstitution of the maxillary sinus architecture and outflow, as well as simultaneously achieving restoration of orbital anatomy. The balloon ensures both orbital floor stability and osteum 


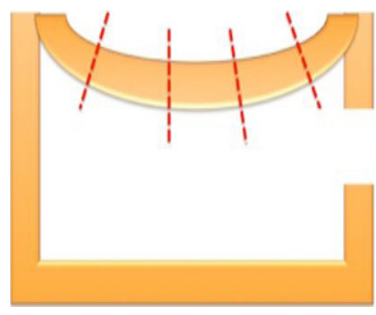

Step 1

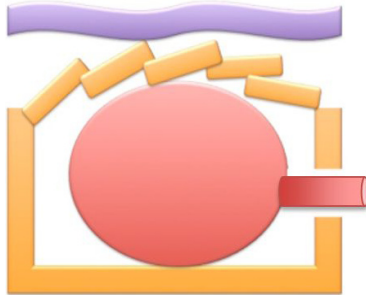

Step 4

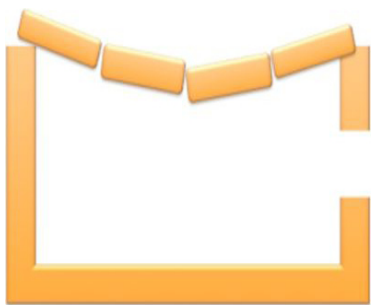

Step 2

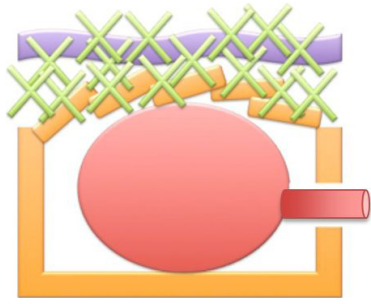

Step 5

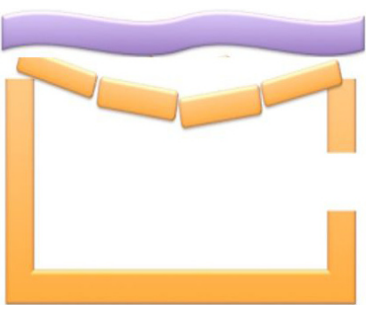

Step 3

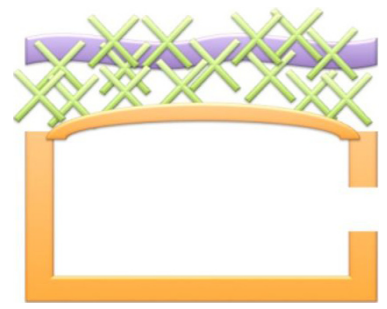

Step 6

Figure 5 Scheme of bone strip floor reconstruction.

Notes: Step I: Through a transconjunctival approach, the orbital floor is accessed. Step 2: Using a \#I5 Bard Parker blade, anterior-to-posterior slats are cut into the orbital floor. Step 3: A cartilage graft/alloplastic implant is used to reconstruct the orbital floor. Step 4: The balloon is introduced to the maxillary sinus endoscopically. When inflated, the slats override like a fan. Step 5: The overriding bone slats, held in place by the cartilage support strut, form a scaffold that heals by fibrosis to reform the orbital floor. Step 6: The balloon is removed in 2 weeks after sufficient time for healing.

patency by acting as a buttress and stent, respectively, during the healing process. The cartilage beam graft may serve as a scaffold to promote healing of the orbital floor in a normalized position and may provide some orbital volume. Based on our anecdotal experience, we believe that onestage orbitosinus reconstruction using a maxillary balloon to support a cartilage graft over bony slats may represent a safe and effective treatment for CMA.

\section{Acknowledgments}

This study had no financial support. This article contains discussion of off-label use of Foley catheter.

\section{Disclosure}

The authors alone are responsible for the content and writing of the article. The authors report no conflicts of interest in this work.

\section{References}

1. Soparkar CN, Patrinely JR, Cuaycong MJ, et al. The silent sinus syndrome. A cause of spontaneous enophthalmos. Ophthalmology. 1994;101: 772-778.

2. Bahgat M, Bahgat $\mathrm{Y}$, Bahgat A. Silent sinus syndrome. BMJ Case Rep. 2012. Available from: http://casereports.bmj.com/content/2012/bcr2012-007198.full.pdf.

3. Davidson JK, Soparkar CN, Williams JB, Patrinely JR. Negative sinus pressure and normal predisease imaging in silent sinus syndrome. Arch Ophthalmol. 1999;117:1653-1654.

4. Blackwell KE, Goldberg RA, Calcaterra TC. Atelectasis of the maxillary sinus with enophthalmos and midface depression. Ann Otol Rhinol Laryngol. 1993;102(6):429-432.
5. Behbehani R, Vacareza N, Bilyk JR, Rubin PA, Pribitkin EA. Simultaneous endoscopic antrostomy and orbital reconstruction in silent sinus syndrome. Orbit. 2006;25(2):97-101.

6. Dinis PB, Branco C, Subtil J. Endonasal endoscopic repair of the orbital floor defect in the silent sinus syndrome. Otolaryngol Head Neck Surg. 2006;135:800-802.

7. Sciarretta V, Pasquini E, Tesei F, Modugno GC, Farneti G. Endoscopic sinus surgery for the treatment of maxillary sinus atelectasis and silent sinus syndrome. J Otolaryngol. 2006;35:60-64.

8. Cardesin A, Escamilla Y, Romera M, Molina JA. Single surgical step for endoscopic surgery and orbital reconstruction of a silent sinus syndrome. Acta Otorrinolaringol Esp. 2013;64:297-299.

9. Brandt MG, Wright ED. The silent sinus syndrome is a form of chronic maxillary atelectasis: a systematic review of all reported cases. Am J Rhinol. 2008;22(1):68-73.

10. Rose GE, Sandy C, Hallberg L, Moseley I. Clinical and radiologic characteristics of the imploding antrum, or "silent sinus," syndrome. Ophthalmology. 2003;110:811-818.

11. Sivasubramaniam R, Sacks R, Thornton M. Silent sinus syndrome: dynamic changes in the position of the orbital floor after restoration of normal sinus pressure. J Laryngol Otol. 2011;125(12):1239-1243.

12. Thomas RD, Graham SM, Carter KD, Nerad JA. Management of the orbital floor in silent sinus syndrome. Am J Rhinol. 2003;17(2):97-100.

13. Soparkar CN, Patrinely JR, Davidson JK. Silent sinus syndrome-new perspectives? Ophthalmology. 2004;111:414-415. [author reply 415-416].

14. Cobb AR, Murthy R, Cousin GC, et al. Silent sinus syndrome. Br J Oral Maxillofac Surg. 2012;50:e81-e85.

15. Sesenna E, Oretti G, Anghinoni ML, Ferri A. Simultaneous management of the enophthalmos and sinus pathology in silent sinus syndrome: a report of three cases. J Craniomaxillofac Surg. 2010;38(6):469-472.

16. Rapidis AD, Liarikos S, Ntountas J, Patel BC. The silent sinus syndrome: report of 2 cases. J Oral Maxillofac Surg. 2004;62:1028-1033.

17. Mavrikakis I, Detorakis ET, Yiotakis I, Kandiloros D. Nonsurgical management of silent sinus syndrome with hyaluronic acid gel. Ophthal Plast Reconstr Surg. 2012;28(1):e6-e7. 


\section{Publish your work in this journal}

Clinical Ophthalmology is an international, peer-reviewed journal covering all subspecialties within ophthalmology. Key topics include: Optometry; Visual science; Pharmacology and drug therapy in eye diseases; Basic Sciences; Primary and Secondary eye care; Patient Safety and Quality of Care Improvements. This journal is indexed on
PubMed Central and CAS, and is the official journal of The Society of Clinical Ophthalmology (SCO). The manuscript management system is completely online and includes a very quick and fair peer-review system, which is all easy to use. Visit http://www.dovepress.com/ testimonials.php to read real quotes from published authors. 